УДК 621.577 .311

DOI

\title{
ПОВЫШЕНИЕ ЭКОНОМИЧНОСТИ ПРОЦЕССОВ ГЕНЕРАЦИИ ТЕПЛОТЫ В КОММУНАЛЬНОЙ ТЕПЛОЭНЕРГЕТИКЕ И ТЕПЛОТЕХНОЛОГИЯХ НА ОСНОВЕ КОМБИНИРОВАННЫХ КОГЕНЕРАЦИОННО-ТЕПЛОНАСОСНЫХ ТЕХНОЛОГИЙ
}

Билека Б.Д., доктор технических наук, Гаркуша Л.к.

Институт технической теплофизики НАН Украины, г.Киев

\begin{abstract}
Аннотация. Наиболее эффективной технологией генерации электрической и тепловой энергии для нужд коммунальной теплоэнергетики и теплотехнологий является комбинированная выработка энергии с использованием современных когенерачионных установок на основе газопориневых двигателей и газотурбинных установок, работающих на природном газе или биогазе. Комбинированная выработка энергии на такой базе существенно снижает затраты топлива в сравнении с традиционной раздельной выработкой электроэнергии на тепловых конденсационных электростанциях или на теплоэлектроцентралях и тепловой на котельных установках. Дальнейшее заметное повышение энергоэффективности прочессов генерации теплоты для рассматриваемых нужд может быть достигнуто путем включения в процесс теплонасосных установок, т.е. создание комбинированных когенерациионо-теплонасосных установок. Они будут иметь наивысшую топливную экономичность в сравнении со всеми существующими в традиционной теплоэнергетике. Это обусловлено целым рядом факторов. Современные когенерационные установки (КГУ) на базе газопоршневых двигателей (ГПД) и газотурбинных установок (ГТУ) имеют электрический к.п.д. выше, чем тепловая электростанция (ТЭС) или теплоэлектрочентраль (ТЭЦ) - 30...45\% и 28...35\%, соответственно. В котлах-утилизаторах более эффективно используется высокотемпературная сбросная теплота двигателей, в результате чего суммарный к.п.д. установок достигает $85 . .88 \%$. Такие установки обеспечивают децентрализацию производства электрической и тепловой энергии, поэтому на автономных КГУ существенно ниже, а иногда практически отсутствуют потери в электрических и тепловых сетях, достигающие в цеентрализованных системах $8 \ldots 12 \%$ и $15 \ldots 30 \%$, соответственно. Немаловажным является и то, что они повышают надежность работы всего объекта, делая его независимым от внешних сетей. Включение в процесс генерации теплоты теплонасосной установки (ТНУ) вызывает заметное повышение энергоэффективности, увеличивая топливную экономичность, благодаря использованию практически даровой низкопотенциальной теплоты природного, промышленного или бытового происхождения, а также высокой эффективности преобразования в ТНУ этой теплоты в теплоту более высокого потенциала с использованием электрической энергии КГУ.
\end{abstract}

Целью работы является оценка перспектив применения комбинированных когенерационнотеплонасосных установок на базе ГПД и ГТУ для повышения энергоэффективности и энергосбережения при генерации теплоты в коммунальной теплоэнергетике и теплотехнологиях, в частности, в процессах суики.

Ключевые слова: когенерационные установки, теплонасосные установки, котельные установки, тепловые электростанции, топливная экономичность.

\section{THE EFFICIENCY IMPROVEMENT OF HEAT GENERATION PROCESSES IN MUNICIPAL HEAT-ENERGY AND DRYING TECHNOLOGIES ON THE BASIS OF COMBINED COGENERATION-HEAT PUMP TECHNOLOGIES}

Bileka B.D., Doctor of Technical Sciences, Garkusha L.K. Institute of Engineering Thermophysics, NAS of Ukraine, Kiev

\begin{abstract}
The most effective technology for electric and heat energy generation for the needs of municipal heatpower and heat technologies is combined power generation (CPG) using modern cogeneration plants based on gas piston engines (GPE) and gas turbine plants (GTP) which work on natural gas or biogas. CPG on such a base significantly reduces fuel costs in comparison with the traditional separate generation of electric power at heat condensing power plants (HPP) or on combined heat and power $(C H P)$ and heat at boiler.

Further noticeable increase in energy efficiency of heat generation processes for the needs under consideration can be achieved by including heat pump plants (HPPs) in the process, which is development of combined cogeneration and heat pump plants. They will have the highest fuel efficiency in comparison with all existing in the tradition-
\end{abstract}

Наукові праці, Том 83, випуск 1 Scientific Works, Volume 83, Issue 1 
Одеська національна академія харчових технологій ІННОВАЦЙНІ РІШЕННЯ ПРОБЛЕМ ЕНЕРГОЗАБЕЗПЕЧЕННЯ

al heat power industry. This is due to a number of factors. Modern CGP based on GPE and GTP have electric efficiency higher than HPP or CHP - 30-45\% and 28-35\%, respectively. In heat recovery boilers, high-temperature waste heat of engines is more efficiently used, resulting in a total efficiency of installations reaches 85-88\%. Such facilities ensure decentralization of electric and heat production, therefore, on autonomous CGPs are much lower, and sometimes there are practically no losses in electric and heat networks, reaching 8-12\% and 15-30\% in centralized systems, respectively. Another important thing is that they increase the reliability of the entire facility, making it independent of external networks. Inclusion in the heat generation process of HPSs causes a significant increase in its energy efficiency, increasing fuel efficiency, thanks to using of almost free low-grade heat of natural, industrial or domestic origin, as well as high conversion efficiency in this HPP heat into higher-potential heat using CGP electric power.

The aim of the work is to evaluate the prospects for the use of combined cogeneration and heat pump plants (CG-HPS) based on GPE and GTP to improve energy efficiency and energy saving in generating heat in municipal heat and heat engineering, in particular, in drying processes.

Key words: cogeneration plants, heat pump plants, boiler plants, heat power station, fuel economy.

Обозначения

\begin{tabular}{|c|c|}
\hline$b$ & удельный расход топлива, кг/кВт; \\
\hline$\Delta \bar{B}$ & относительная топливная экономичность установок; \\
\hline$N_{Э_{K \Gamma Y}}$ & электрическая мощность КГУ, кВт; \\
\hline$N_{Э_{(T H Y-T Э C)}}$ & электрическая мощность автономной ТНУ, потребляемая от ТЭС; \\
\hline ГПД & газопоршневый двигатель; \\
\hline ГTУ & газотурбинная установка; \\
\hline$K$ & котел; \\
\hline KBЭ & комбинированная выработка энергии; \\
\hline КГ-ТНУ & комбинированная когенерационно-теплонасосная установка; \\
\hline$(K \Gamma-T H У)-K$ & КГ-ТНУ- котел; \\
\hline $\begin{array}{l}(К \Gamma-T H У)-(T Э C- \\
T H У)\end{array}$ & $\begin{array}{l}\text { КГ-ТНУ теплонасосная установка-тепловая электростанция - теплонасосная } \\
\text { установка; }\end{array}$ \\
\hline$K Г У-(T Э C-K)$ & когенерационная установка-тепловая электростанция-котел; \\
\hline THY & теплонасосная установка; \\
\hline$T Э C$ & тепловая электростанция; \\
\hline ТЭЦ & теплоэлектроцентраль; \\
\hline$K_{T_{K T Y}}$ & тепловой коэффициент КГУ; \\
\hline$K_{\text {THY }}$ & коэффициент трансформации теплоты автономной ТНУ; \\
\hline$K_{T H Y}^{\prime}$ & $\begin{array}{l}\text { коэффициент трансформации теплоты ТНУ в составе комбинированной КГ- } \\
\text { ТНУ; }\end{array}$ \\
\hline$Q_{P_{K}}^{H}$ & низшая теплотворная способность топлива котла, кДж/кг; \\
\hline$Q_{P_{K \Gamma Y}^{H}}^{H}$ & низшая теплотворная способность топлива КГУ, кДж/кг; \\
\hline$\eta_{K}$ & тепловой к.п.д. котла; \\
\hline$\eta_{Э_{K Г У}}$ & электрический к.п.д. КГУ; \\
\hline$\eta_{Э_{T \ni C}}$ & электрический к.П.Д. ТЭС; \\
\hline$\eta_{\Pi T C}$ & коэффициент, учитывающий потери в тепловых сетях; \\
\hline 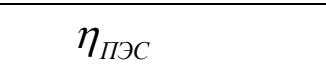 & коэффициент, учитывающий потери в электрических сетях; \\
\hline
\end{tabular}

Методика оценки топливной экономичности установок. Известно достаточно большое количество опубликованных работ, посвященных методикам оценки топливной экономичности энергетических установок, генерирующих электрическую и тепловую энергию, в частности $[1,2,3]$. Однако они в определенной степени сложны, требуют дополнительной информации, кроме знания стандартных параметров установок, не обладают универсальнолстью. 
В Институте технической теплофизики НАН Украины предложена достаточно простая и универсальная методика сравнительной оценки относительной интегральной топливной экономичности энергетических установок, генерирующих теплоту и электроэнергию и, по сути, формирующей себестоимость получаемой энергии [4]. Уровень потенциалов высокотемпературных потоков сбросной теплоты ГПД и ГТУ - выхлопных газов двигателей существенно превышает уровень целевого теплоносителя для теплоснабжения и горячего водоснабжения. В ГТУ этот источник, в силу конструктивных особенностей, является практически единственным. В ГПД кроме того есть источники с более низкими температурными потенциалами. К ним относятся теплота систем охлаждения двигателя и турбонагнетателя, маслоохладителя. Тепловые потоки от этих систем используются на этапах предварительного подогрева целевого теплоносителя.

Методика базируется на использовании основных уравнений балансов тепловых и электрических мощностей установок при условии выработки ими одинакового количества электрической и тепловой энергии. После соответствующих преобразований и обезразмеривания конечных выражений получаем функциональные зависимости относительной топливной экономичности сравниваемых установок, описываемые соотношениями безразмерных термодинамических параметров и показателей (к.п.д. установок, тепловых коэффициентов двигателей, коэффициентов трансформации теплоты ТНУ). При этом сравнительные базы различных установок могут отличаться.

При проведении сравнения централизованных и децентрализованных (автономных) энергетических установок в уравнения вводятся коэффициенты, учитывающие величины электрических и тепловых потерь в сетях.

При проведении сравнительного анализа установок должны быть известны или заданы не только величины коэффициентов полезного действия двигателей, но и их тепловые коэффициенты, а также коэффициенты трансформации теплоты ТНУ. Однако в проектировочных задачах при выборе двигателя КГУ при задании величины к.п.д., величина его теплового коэффициента, выражающего отношение тепловой и электрической мощности двигателя, неизвестна. В тоже время эти величины физически детерминированы и их соотношение не может изменяться произвольно. Путем статистической обработки достаточно большого количества характеристик двигателей КГУ-ГПД и ГТУ была получена эмпирическая зависимость тепловых коэффициентов двигателей от электрических к.п.д.. Она представлена следующим выражением:

$$
K_{T_{K Г У}}=0,362 \cdot \eta_{Э_{K Г Y}}^{-1,25} .
$$

В работе представлены результаты анализа топливной экономичности ряда нескольких наиболее распространенных в теплоэнергетике способов генерации тепловой и электрической энергии в сравнении с её генерацией на основе комбинированных когенерационно-теплонасосных технологий, поскольку электрической базой комбинированных установок являются когенерационные установки, вносящие свой вклад в повышение энергоэффективности, их характеристики представляют самостоятельный интерес. Поэтому анализ топливной экономичности КГУ в первую очередь был проведен путем сравнения с альтернативной, раздельной выработкой электроэнергии на ТЭС, а теплоты в котельной.

Сравнение КГУ с раздельной выработкой энергии. Относительная интегральная топливная экономичность КГУ в сравнении с раздельной выработкой электроэнергии и теплоты на ТЭС и в котельной установке при использовании газового топлива может быть представлена следующей зависимостью:

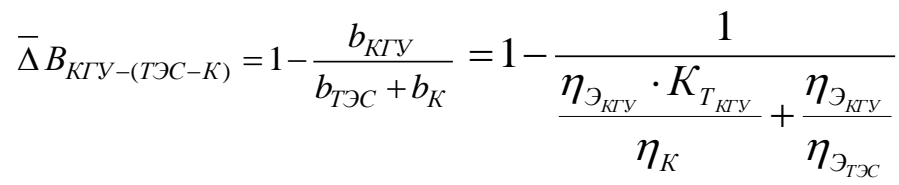

или с учетом зависимости (1)

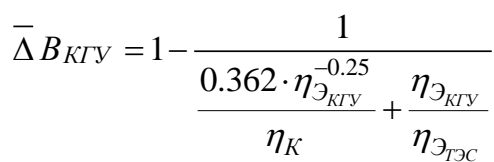

Условием существования топливной экономии сравниваемых технологий является соблюдение неравенства:

$$
\left(\frac{0.362 \cdot \eta_{Э_{K T Y}^{-0.25}}^{-}}{\eta_{K}}+\frac{\eta_{Э_{K T Y}}}{\eta_{Э_{T Э C}}}\right)>1 .
$$

Некоторые результаты расчетов относительной топливной экономичности рассматриваемых технологий представлены на рис. 1. 


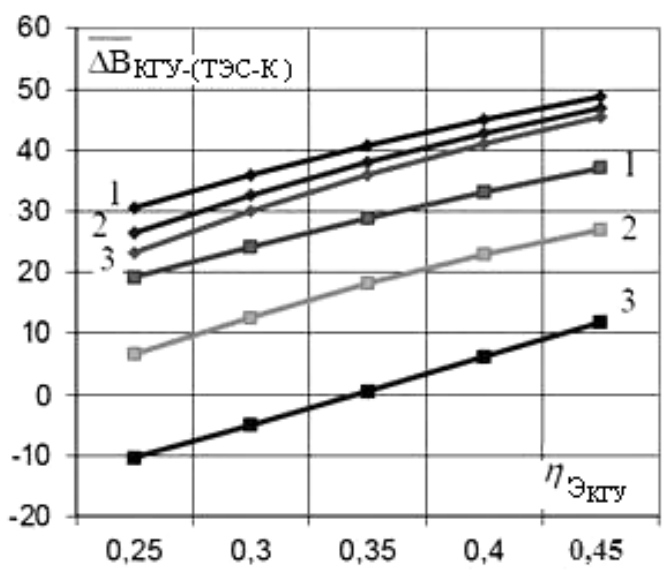

Рис. 1. Зависимость относительной экономии топлива КГУ при генерации энергии в сравнении с котельной установкой при различных величинах к.п.д. котла $\left(\eta_{\kappa}\right)$ и ТЭС при различных величинах электрического к.п.д. ТЭС $\left(\eta_{Э_{T \ni}}\right)$ от величины электрического к.п.д. двигателя кГУ $\left(\eta_{Э_{K T Y}}\right)$.

$$
\begin{aligned}
& \diamond-\eta_{Э_{T Э C}}=\mathbf{O}, 33 ; \quad \square \eta_{Э_{T Э C}}=0,45 \\
& \mathbf{1}-\eta_{\kappa}=0,75 ; \mathbf{2}-\eta_{\kappa}=0,85 ; \mathbf{3}-\eta_{\kappa}=0,94
\end{aligned}
$$

В расчетах КГУ не учитывались электрические и тепловые потери в сетях, поскольку в обоих случаях рассматривался случай транспорта вырабатываемой энергии через внешние сети, т.е. случай централизованной поставки энергии и, следовательно, одинаковых потерь.

При децентрализованной схеме поставки энергии КГУ и централизованной раздельной от ТЭС и котельной необходимо учитывать сетевые потери электроэнергии и теплоты. Таким образом, выражение для расчета относительной топливной экономичности для этого случая будет иметь вид:

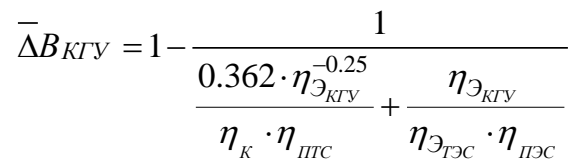

Поскольку величины транспортных потерь в тепловых и электрических сетях могут достигать $8 \ldots 12 \%$ и $15 \ldots 30 \%$ соответственно, то величины коэффициентов, учитывающих потери в них, соответственно составят $0,92 \ldots 0,88$ и $0,85 \ldots 0,7$. Вполне очевидно, что это обеспечит ещё большую экономию топлива в децентрализованных системах теплоснабжения с КГУ.Можно видеть, что для рассмотренных случаев величины относительной топливной экономичности систем электротеплоснабжения на базе КГУ в сравнении с ТЭС и котельной будет находиться на уровне от $8 \ldots 12$ до $30 \ldots 50$ \%. Наиболее высокий уровень экономии топлива будет наблюдаться при замене старых котельных с к.п.д. котлов $0,75 \ldots 0,85$. Но и при замене более совершенных котлов с уровнем к.п.д. 0,94 на КГУ возможная экономия топлива при электрическом к.П.д. ТЭС 0,33 составит $4 \ldots 12 \%$.

Сравнение комбинированной КГ-ТНУ и котельной установки. Сравнение по топливной экономичности двух видов генерации теплоты на базе комбинированной когенерационно-теплонасосной установки и котла, использующих газовое топливо, при условии выработки КГ-ТНУ конечного продукта только в виде теплоты может быть проведено с использованием зависимости:

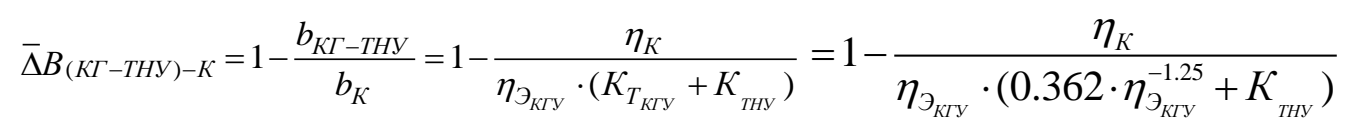

Положительный эффект в экономии топлива будет существовать только при соблюдении неравенства вида:

$$
\eta_{Э_{K T Y}} \cdot\left(0.362 \cdot \eta_{Э_{K T Y}^{-1.25}}+K_{T H Y}\right)>\eta_{K}
$$

При сравнении с котельной установкой, работающей на другом виде топлива, чем КГУ, выражение для определения топливной экономичности в эквиваленте теплотворной способности топлива КГУ будет иметь вид:

Наукові праці, Том 83, випуск 1 


$$
\bar{\Delta} B_{(K T-T H Y)-K}=1-\frac{\eta_{K}}{\eta_{Э_{K T Y}} \cdot\left(0.362 \cdot \eta_{Э_{K T Y}}^{-1.25}+K_{T H Y}\right)} \cdot \frac{Q_{H_{K}}^{P}}{Q_{H_{K T-T H Y}}^{P}} .
$$

Расчеты относительной топливной экономичности КГ-ТНУ в сравнении с газовой котельной установкой приведены на рис. 2 в виде зависимостей экономичности от электрического к.п.д. КГУ при диапазоне изменения его 0,25...0,428 при фиксированных величинах КТНУ, равных 1,5; 3,5; 5 . Кривые построены для расчетных вариантов сравнений при к.п.д. котельных установок, равных 0,$75 ; 0,85 ; 0,95$.

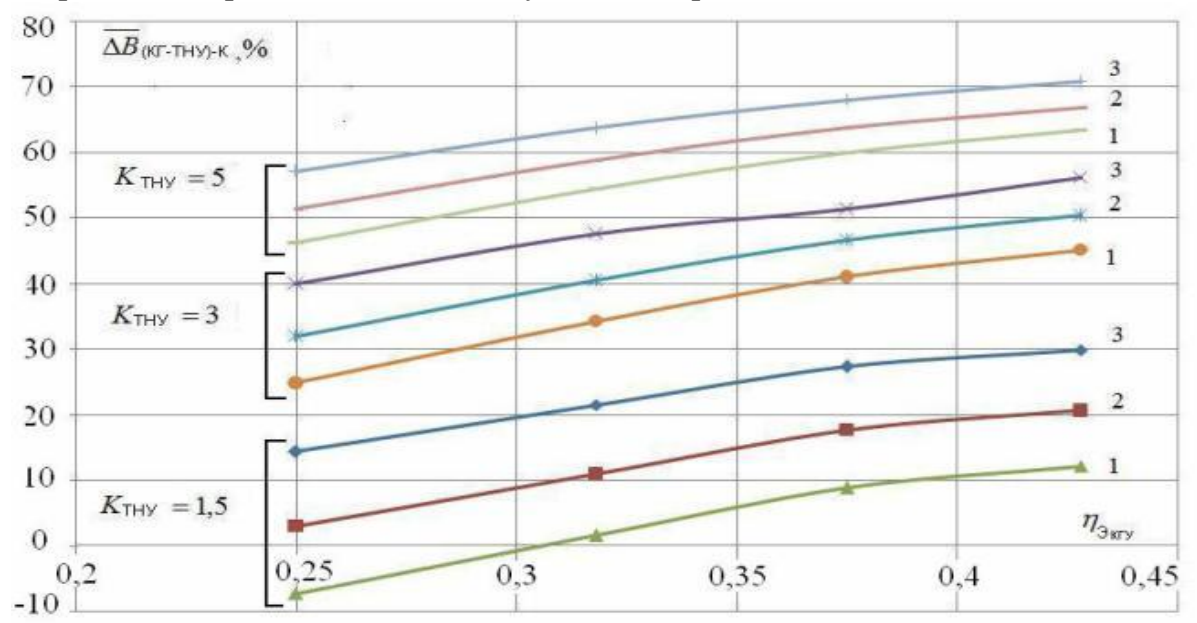

Рис. 2. Зависимость относительной экономии топлива КГ-ТНУ при генерации теплоты в сравнении с котельной установкой от величины электрического к.п.д. Двигателя КГУ при различных величинах теплового к.п.д. котла $\left(\eta_{K}\right)$ и коэффициента тепловой трансформации $\left(K_{T H Y}\right)$.

$$
\text { 1- } \eta_{\kappa}=0,94 ; 2-\eta_{\kappa}=0,85 ; 3-\eta_{\kappa}=0,75
$$

Можно видеть более высокую эффективность генерации теплоты у КГ-ТНУ по сравнению с котельными

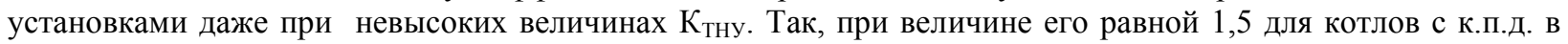
диапазоне от 0,95 до 0,75 , топливная экономичность будет изменяться от 2 до $32 \%$, при К такое возрастание экономичности составит уже $33 \ldots 62$ \%. Это наглядно подтверждает перспективность модернизации котельных не только с котлами, имеющими невысокие тепловые к.п.д., но и с более эффективными современными котлами

4. Сравнение комбинированной КГ-ТНУ с электрокотлом, потребляющим сетевую электроэнергию. Сравнение этих двух видов генерации теплоты по относительной топливной экономичности можно провести по полученной зависимости следующего вида:

$$
\begin{aligned}
& \Delta \overline{\boldsymbol{B}}_{(K T-T H Y)-K_{\jmath}}=1-\frac{b_{(K T-T H Y)-K_{\ni}}}{\mathrm{b}_{\mathrm{k}_{\ni}}}=1-\frac{\eta_{\kappa_{\jmath}}}{\eta_{\Im_{K T Y}}\left(K_{T_{K T Y}}+K_{T H Y}\right)}=1-\frac{\eta_{\kappa_{\ni}}}{\eta_{\Im_{K T Y}} \cdot\left(0,362 \cdot \eta_{э_{K T Y}}^{-1,25}+K_{T H Y}\right)}
\end{aligned}
$$

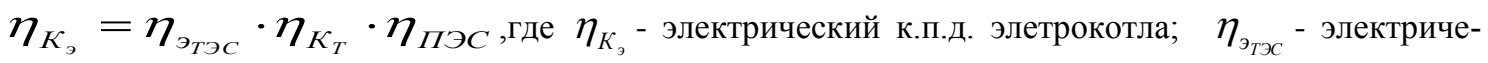

ский к.п.д. ТЭС; $\eta_{\kappa_{T}}$ - тепловой к.п.д. электрокотла с учетом его тепловых потерь; $\eta_{\Pi \ni С}$ - коэффициент, учитывающий электрические потери в сетях. С учетом этого зависимость будет иметь вид:

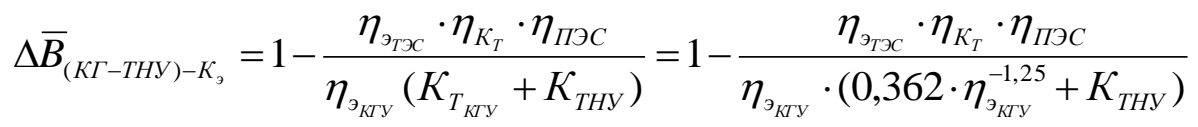

Экономия топлива будет наблюдаться при условии выдерживания следующего неравенства:

$$
\eta_{э_{K T Y}} \cdot\left(0,362 \cdot \eta_{丂_{K T}}^{-1,25}+K_{T H Y}\right)>\eta_{丂_{T Э C}} \cdot \eta_{K_{T}} \cdot \eta_{\Pi \ni C}
$$

Результаты расчетов относительной топливной экономичности комбинированной КГ-ТНУ и электрокотла, использующего сетевую электроэнергию от ТЭС, представлены на рисунке 3 в виде зависимостей изменения относительной топливной экономичности КГ-ТНУ от величины электрического КПД двигателя КГУ в диапазоне изменения последних от о,25 до 0,428. 


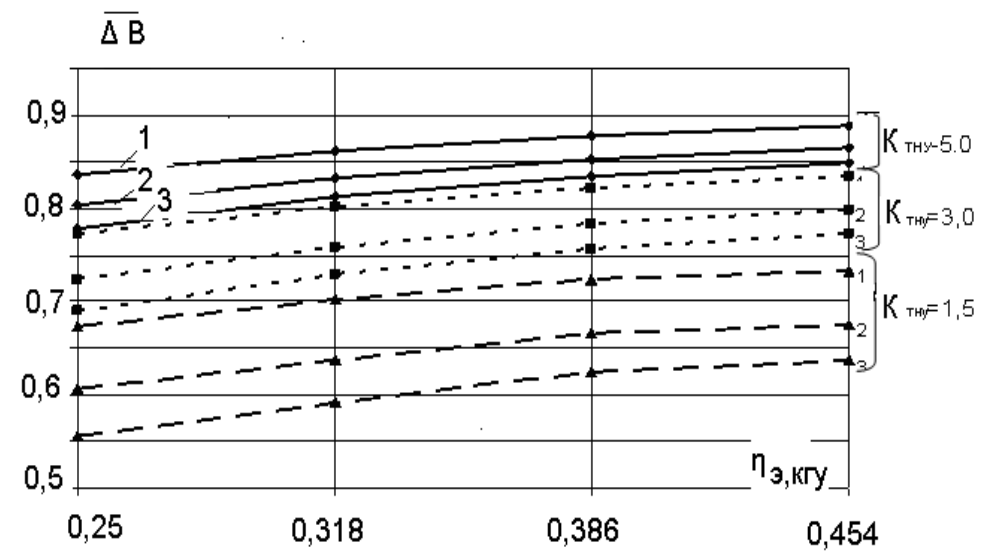

Рис. 3. Относительная топливная экономичность комбинированной КГ-ТНУ и электрокотла, использующего сетевую электроэнергию от ТЭС.

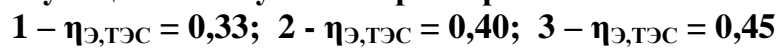

При этом рассматривались варианты КГ-ТНУ, в которых величины коэффициентов трансформации теплоты ТН изменялись от 1,5 до 5. Расчеты проведены при сравнении с ТЭС, электрический КПД которых изменялся в пределах от 0,33, характерных для большинства ТЭС Украины, до 0,45. Величина электрических потерь в сетях принята равной $12 \%$

Можно видеть, что даже при невысоких величинах коэффициента тепловой трансформации в КГ-ТНУ, порядка 1,5, экономия топлива находится на уровне $0,67 \ldots 0,73$, а при коэффициенте трансформации, равном 5, она достигает $0,84 \ldots 0,89$. Возрастание КПД ТЭС сравнительно слабо влияет на изменение экономии топлива, несколько снижая ее, что позволяет сделать вывод о серьезных и стабильных преимуществах КГТНУ в генерации теплоты.

5. Сравнение комбинированной КГ-ТНУ с автономной ТНУ, потребляющей сетевую электроэнергию. Выбор путей использования ТНУ при генерации теплоты в системах теплоснабжения имеет важное значение в повышении их энергоэффективности. Одной из таких задач является оценка эффективности применения комбинированных КГ-ТНУ вместо автономных ТНУ, потребляющих сетевую электроэнергию ТЭС или ТЭЦ.

Относительная топливная экономичность КГ-ТНУ в сравнении с автономной ТНУ, работающей на сетевой энергии ТЭС при одинаковой тепловой мощность определяется зависимостью:

$$
\bar{\Delta} B_{(K \Gamma-T H У)-(T H У-T Э C)}=1-\frac{b_{K \Gamma-T H У}}{b_{T H У-T Э C}}=1-\overline{\mathrm{N}} \frac{\eta_{Э_{T Э C}} \cdot \eta_{\Pi Э C}}{\eta_{Э_{K Г У}}}
$$

Можно показать, что величина относительной электрической мощности КГ-ТНУ зависит от теплотехнических параметров установок следующим образом

$$
\overline{\mathrm{N}}=\frac{\mathrm{N}_{\Im_{K T У}}}{\mathrm{~N}_{Э_{(Т H У-T Э C)}}}=\frac{K_{T H y}}{K_{T_{K T Y}}+K_{T H y}^{\prime}}
$$

При этом при выбранных параметрах КГУ и заданной величине К комбинированной КГ-ТНУ определяется следующей зависимостью:

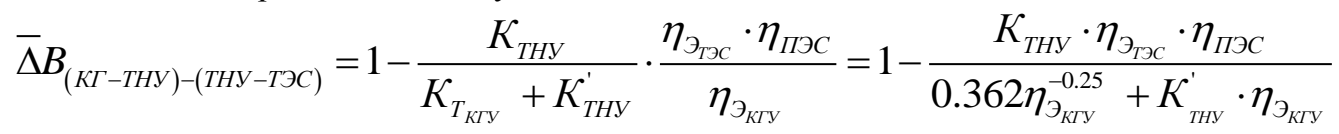

Выбор параметров рассматриваемых установок, проведение сравнений их характеристик следует проводить с учетом зависимостей 9,10,11.

Преимущество комбинированных КГ-ТНУ в топливной экономичности в сравнении с автономными ТНУ будет проявляться при соблюдении следующего неравенства 


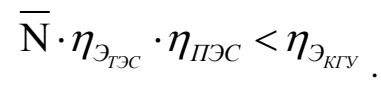

Из этого условия видно, что выбор соотношения электрических мощностей, затрачиваемых на привод ТН в комбинированной КГ-ТНУ и автономной ТНУ, играет важную роль как при определении рабочих характеристик установок, так и при проведении сравнительного анализа наравне с термодинамическими параметрами и тепловыми характеристиками установок. Некоторые результаты расчетов величин коэффициентов тепловой трансформации, а также относительной топливной экономичности КГ-ТНУ и автономной ТНУ представлены на рисунке 4. Расчеты проведены в следующих диапазонах изменения основных параметров: отношение электрических мощностей ТНУ в составе КГ-ТНУ и автономной ТНУ от 0,3 до 0,7 ; тепловых коэффициентов КГУ от 1 до 2; величин КТНУ автономных ТНУ от 2 до 5, а в составе комбинированных установок от 1,5 до 6; величин электрических к.п.д. ТЭС от 0,3 до 0,4, а КГУ от 0,25 до 0,428.

Результаты расчетов относительной экономии топлива комбинированной КГ-ТНУ при изменении К' комбинированной установки для 3 -х значений $\overline{\mathbb{N}}$ представлены на рис. 4.

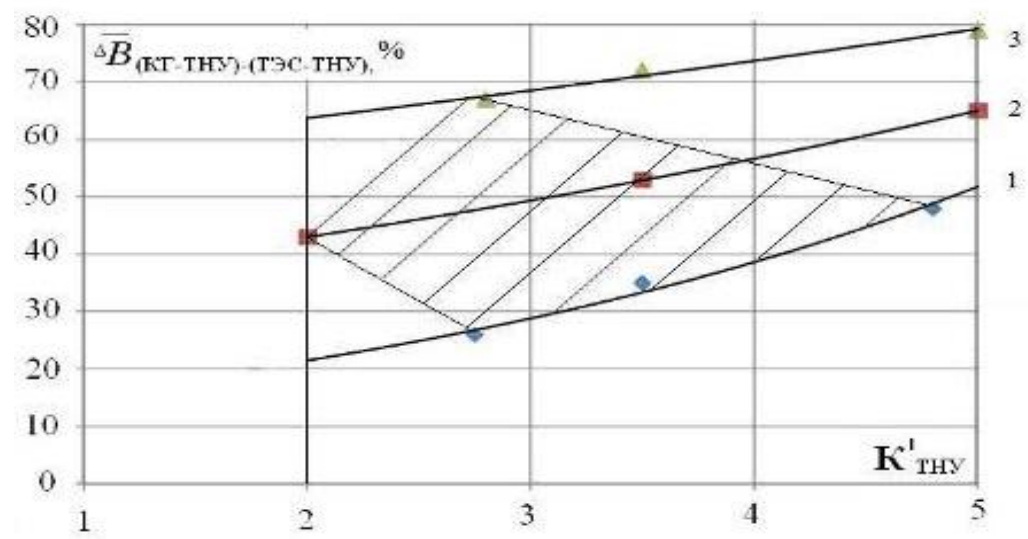

Рис. 4. Зависимость относительной топливной экономичности КГ-ТНУ в сравнении с автономной ТНУ, потребляющей электроэнергию ТЭС, от величины коэффициента трансформации теплоты ТНУ в составе КГ-ТНУ при различных величинах относительных электрических мощностей $(\bar{N})$ для $\eta_{\text {этэ }}=0,33 . \quad \mathbf{1}-\bar{N}=0,7 ; \mathbf{2}-\bar{N}=0,5 ; \mathbf{3}-\bar{N}=0,3$

Изменение зависимости относительной экономии топлива определяется особенностями изменения соотношений величин коэффициентов трансформации теплоты тепловых насосов, величин электрических к.п.д. КГУ и ТЭС и теплового коэффициента двигателя КГУ и имеет сложный характер. Заштрихованная область соответствует области реально возможных изменений коэффициентов трансформации тепловых насосов. Диапазон изменения относительной топливной экономичности, расположенный между кривыми относительных электрических нагрузок 0,3 и 0,7, лежит в пределах от $25 \ldots 49$ \% до $65 \ldots 68$ \%. Зависимость построена для варианта работы ТЭС с электрическим к.п.д. - 0,33.

Наиболее высокий уровень экономичности наблюдается на участке кривой при относительной мощности ТН КГ-ТНУ, равной 0,3. Однако он достаточно узок по изменению диапазона К номичность снижается. Такой характер изменения объясняется тем, что при меньших значениях $\overline{\mathbb{N}}$ и фиксированной величине $\mathrm{K}_{\mathrm{THy}}$, возрастает доля теплоты, вырабатываемой ТН комбинированной установки с

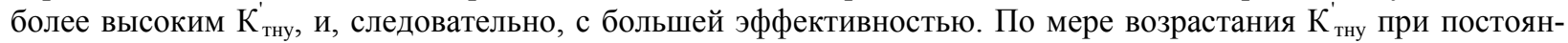
ной величине $\bar{N}$ возрастает доля теплоты, более эффективно вырабатываемой ТН КГ-ТНУ, а доля сбросной теплоты двигателя в данном случае, являющейся менее эффективной, снижается, что отражается на росте топливной экономичности комбинированной КГ-ТНУ.

Большие возможности повышения энергоэффективности теплотехнологий может обеспечить применение комбинированных когенерационно-теплонасосных установок [5,6]. Это касается, прежде всего, таких высокоэнергозатратных технологических процессов, как сушка продуктов агропромышленного сектора, а также непродовольственных материалов [7].

Основным видом промышленного сушильного оборудования являются сушильные установки конвективного типа, в которых в качестве сушильного агента используется атмосферный воздух.

Генерация теплоты в сушильных установках такого типа осуществляется преимущественно двумя видами теплогенераторов. К первым можно отнести паровые воздухоподогреватели на базе парового котла и 
паровоздушного калорифера. Ко вторым относятся воздухоподогреватели с различными типами топочных устройств, использующих различные виды топлива - газ, жидкое, твердое.

Котельные установки, применяемые в сушильных комплексах, имеют тепловой к.П.д. на уровне $0,7 \ldots 0,8$. Коэффициент полезного действия воздухонагревателей с топочными устройствами находятся в пределах $0,6 \ldots 0,7$, что свидетельствует о невысокой энергетической и эксергетической эффективности процессов генерации теплоты в этих устройствах в сравнении с комбинированной выработкой энергии на базе КГ-ТНУ. Несмотря на некоторую приближенность в сравнительной оценке тепловой экономичности рассматриваемых типов теплогенераторов с котельной установкой, для её проведения можно воспользоваться рассмотренной выше методикой сравнения котла с КГ-ТНУ.

Если принять среднее значение величины теплового к.п.д. теплогенераторов сушилок равным 0,7, то, в диапазоне изменения электрических к.п.д. двигателя КГУ от 0,25 до 0,428, а коэффициента трансформации теплоты ТН от 1,5 до 5, относительная топливная экономичность сушилок при замене существующих теплогенераторов на комбинированные КГ-ТНУ в соответствии с зависимостью (5), возрастет от 0,18...0,34 до $0,6 \ldots 0,73$. Это свидетельствует о высоких возможностях снижения расхода топлива на генерацию теплоты в сушильных технологиях при использовании комбинированных КГ-ТНУ. Еще одним преимуществом, снижающим энергозатратность процессов сушки продуктов, требующих охлаждения его в конце процесса, в частности в зерносушилках, является возможность использования для этого сбросной теплоты греющего теплоносителя испарителя ТН (воздуха или воды). Возможности и реализация такого подхода повышения энергоэффективности процесса сушки были показаны в [8] и на проекте модернизации зерновой сушилки шахтного типа производительностью 13,5 т/час на базе КГУ с ГПД электрической и тепловой мощностью 315 и 430 кВт и теплового насоса мощностью 840 кВт [9]. Для досушки и охлаждения зерна используется охлажденный в испарителе воздух, который после выхода из сушилки подается в конденсатор и после нагрева поступает в зону досушки. Таким образом, сбросная теплота испарителя и конденсатора ТН включается в общий тепловой баланс процесса. В целом такой подход позволяет снизить энергозатраты процесса сушки не менее чем в 1,5..2 раза, а энергозатраты на удаление 1 кг влаги довести до 2200...3000 кДж/кг.

\section{Выводы}

1. Полученные количественные оценки относительной топливной экономичности комбинированных когенерационно-теплонасосных установок в сравнении с традиционными способами генерации теплоты с использованием котельных установок, электрокотлов и автономных теплонасосных установок, потребляющих сетевую электроэнергию, подтверждает более высокую энергоэффективность комбинированных установок, перспективность и целесообразность их применения в коммунальной теплоэнергетике и теплотехнологиях.

2. Предложенная методика сравнительной оценки относительной интегральной топливной экономичности энергетических установок может быть использована как при проведении сравнительного анализа существующих установок, так и при проведении проектировочных расчетов на этапе предварительного выбора тепловых схем и рабочих параметров установок.

\section{References}

1. Klimenko, V.I., Mazur, A.I., Sigal, A.I. (2011) Kogeneratsionnyie sistemyi s teplovyimi dvigatelyami. Spravochnoe posobie, Chast 2, Gazoburbinnyie kogeneratsionnyie tehnologii, Kiev IPTs ALKOM NAN Ukrainyi, 788.

2. Dubovskiy, S.V. (2014) EnergoekonomIchniy analiz spoluchennih sistem generatsiyi elektrichnoyi energiyi i teploti. Naukova dumka.182.

3. Tsatsaronis, G., Winhold, M. (1995) Exergoeconomic analaysis and evaluation of energy-conversion plant Energy. 16(1). 81-94.

4. Bileka, B.D., Sergienko, R.V., Kabkov, V.Ya. (2010). Ekonomichnost kogeneratsionnyih i kombinirovannyih kogeneratsionno-teplonasosnyih ustanovok s gazoporshnevyimi i gazoturbinnyimi dvigatelyami. Aviatsionno-kosmicheskaya tehnika i tehnologii. Vyipusk, 7(74). 25-29.

5. Snezhkin, Yu.F., Shavrin, V.S., Chalaev, D.M., Shapar, R.A. (2008). Primenenie teplonasosnyih tehnologiy $\mathrm{v}$ energetike. Ekotehnologiya i resursosberezhenie. 3. 11-15.

6. Snezhkin, Yu.F. (2015). Energooschadni teplonasosni tehnologiyi dlya sistem teplopostachannya zhitlovokomunalnogo gospodarstva i promislovosti. Visnik NAN Ukrayini. 7. 23-30.

7. Snezhkin, Yu.F., Shapar, R.A. (2009) Analiz faktorov povyisheniya effektivnosti protsessa sushki termolabilnyih materialov. Promyishlennaya teplotehnika. 31(7). 110-112.

8. Kliopova, I., Stanicki, J. (2006) Application Energy waste utilization techniques in Lithuanian. Environ.res., engineering and management. 1(35). 32-42.

9. Snezhkin, Yu.F., Ulanov, M.M. (2016) Virobnitstvo ta kompleksne vikoristannya energiyi kogeneratsiynih ustanovok v zernosusharnih kompleksah. Hranenie i pererabotka zerna. 2. 20-32.

Отримано в редакцію 04.04.2019

Received 04.04.2019

Прийнято до друку 16.06.2019

Approved 16.06.2019

Наукові праці, Том 83, випуск 1

Scientific Works, Volume 83, Issue 1 